\title{
Relações nem sempre amistosas: os egípcios e os seus mortos
}

\author{
MARGARET MARCHIORI BAKOS \\ Pontifícia Universidade Católica do Rio Grande do Sul
}

\begin{abstract}
RESUMO: Como o egípcio considerava a morte uma extensão da vida, era fato comum que os antigos egípcios buscassem comunicar-se com seus parentes mortos. O propósito deste trabalho é mostrar que, em muitas cartas, o medo de alguma coisa foi uma das mais importantes razões para este tipo de comunicação.

PALAVRAS-CHAVE: Egito, cartas, mortos, medo.
\end{abstract}

\section{Introdução}

Os antigos egípcios manifestaram com extraordinária clareza, nas decorações das tumbas e em vários textos, sua certeza sobre a finitude da vida humana terrena. É encantador e confortante observar a simplicidade com que encaravam essa realidade.

A preparação para a outra vida, os objetos requintados do morto e as provisões que colocavam nas tumbas, além de simples atos de religiosidade e de amor dos familiares. tinham um outro significado?

Acreditamos que havia mais a ser entendido nessas ações. Os egípcios viam os mortos como entidades com sabedoria e poderes capazes de iluminar a vida dos sobreviventes. Diferentemente de outras sociedades, os defuntos, para os egípcios, não eram na essência malignos. Como os vivos, eles sofriam de oscilações no humor, dependendo do tipo de relação afetiva que os sobreviventes com eles mantinham. Tais laços sentimentais faziam com que os defuntos protegessem ou atormentassem os parentes vivos.

Pelo conteúdo dos textos funerários vemos que, na ótica dos egípcios, os defuntos agiam como os "vivos", morando em tumbas, como se fossem suas casas terrenas. Os hieróglifos, representando da mesma forma a Capela Funerária e a Casa da Eternidade, revelavam a estreita relação que eles estabeleciam entre essas moradas (Spencer,1982, p.72).

Neste trabalho buscamos, através da análise de cartas dos egípcios para os seus mortos, mostrar um aspecto peculiar daquele período: o medo de que os mortos pudessem incomodar os vivos, se por estes fossem magoados ou esquecidos.

Por medo, entendemos um sentimento de grande inquietação ante a noção de um perigo real ou imaginário (Ferreira, 1986, p.1110).

Nosso objetivo é evidenciar aspectos que expressem susto ou pavor de perdas materiais, 
de doenças e até mesmo de não vir a ter filhos, em textos escritos pelos vivos para parentes falecidos. É importante referir que os remetentes também amedrontavam os destinatários. "Quem vai servir água para você, se os que reverenciam o abandonarem?" Era uma questão crucial para os mortos, em uma sociedade onde este líquido, provido à população pelas enchentes anuais do Nilo, era fundamental para a vida.

Essa correspondência bizarra pode, com certeza, revelar outras nuanças daqueles homens, sobretudo a cumplicidade que estabeleciam entre si, independentemente das relações de carne e de osso.

\section{Cartas aos mortos}

As primeiras cartas dos egípcios aos seus mortos datam do Reino Antigo. Ao longo do Primeiro Período Intermediário e no decorrer das dominações persa e greco-romana, elas foram muito populares. Os egiptólogos concordam em indicar a XIX dinastia, a dos Ramsés, como a fase clássica dessa correspondência peculiar.

Na visão de Wente, tais documentos funcionavam basicamente como petições, feitas em forma epistolar, através das quais os egípcios buscavam comunicar-se com os seus mortos.

Eram mensagens geralmente escritas em grafia cursiva hierática, encontradas em papiros, estelas ou em vasilhas, tipo bacias, as quais juntamente com as oferendas, eram depositadas nas tumbas dos mortos.

Muitas vezes as cartas eram redigidas por pessoas comuns, de ambos os sexos ${ }^{1}$. É importante salientar que, de outro lado, fazer a correspondência de particulares era certamente um meio de vida para escribas sem uma atividade regular.

Nas missivas aos falecidos, os vivos pediam geralmente para não serem perseguidos por espíritos descontentes e malvados. Pela crença no poder dos mortos de influenciar acontecimentos, os terrenos ainda pediam auxílio nas disputas com os próprios vivos.

Essas cartas conservaram-se em sítios, localizados além das áreas de aluvião, como a ilha de Elefantina, El-Lahun e Gurob. E em outros locais secos, como as necrópoles de Saqara, de Mênfis, dos vales Tebanos e de Tell el Amarna.

A primeira edição da correspondência de vivos para mortos foi feita por Gardiner e Sethe, em 1928, revisada por Gunn, em 1930. A partir dessas transliterações, foram feitos artigos que reproduziram e modificaram, em alguns casos, as versões originais, e que foram divulgados em fontes diversas. Para este artigo, dispomos da atualização recente de Edward Wente em Letters from Ancient Egypt e de Edda Bresciani, em Letteratura e Poesia Dell'Antico Egitto.

A persistência desses egiptologistas em resgatar o sentido de missivas, escritas em épocas tão remotas e em linguagem desaparecida, permite atualmente rever aspectos, no mínimo, pitorescos e inusitados, da vivência diária em tempos antigos.

Da leitura das cartas, procuramos recuperar os sentimentos dos missivistas, transcrevendo alguns dos textos que, embora fragmentados e vagos, indiciam essas manifestações humanas.

Na impossibilidade de analisar, em um artigo apenas, todas as cartas disponíveis, escolhemos algumas que tratam do relacionamento familiar. Examinamos casos da correspondência entre os cônjuges: de mulher para o marido morto e de homem para a esposa morta. Examinamos cartas de filhos para os pais mortos e de genitora para o seu descendente falecido. Todas elas apresentam uma temática instigante e reveladora dos sentimentos humanos.

\section{1) Carta de uma mulher (Irti) para o marido morto (Sankhenptah).}

Da VI Dinastia, a carta foi descoberta na tumba de Sanekhenptah, em Saqara, escrita em tela de linho ${ }^{2}$. É uma mulher que a endereça ao marido, em defesa do filho de ambos: 
Possa $\mathrm{Ha}^{3}$, senhor do Ocidente, e possa Anubis, senhor dos mortos, ajudálo, como nós ambos desejamos.

Esta é para lembrá-lo do fato de que um agente de Behezti veio buscar couro enquanto eu estava sentada ao seu lado, quando Iy, o filho de Irti (isto é, meu) foi forçado a afirmar pelo agente de Behezti que você tinha dito, "Mantenha-o escondido por medo de Iy o mais velho! Possa a madeira desta cama que me suporta apodrecer se ofilho de um homem for privado do mobiliário de sua casa."

Na verdade, a mulher Wabut veio junto com Izezi, e eles juntos devastaram a sua casa. Era com o fito de enriquecer Izezi que ela removeu tudo o que tinha aqui, ambos desejando empobrecer o seu filho e enriquecer o filho de Izezi. Ela levou lazet, Iti, e Anankhi de você, e ela está levando embora todos os seus criados pessoais depois de tirar tudo o que havia na sua casa. Você pode ficar calmo com tudo isto? Eu preferia estar ao seu lado a ver o seu filho dependendo do filho de Izezi.

Estimule seu pai Iy contra Behezti! Insurja-se e apresse-se contra ele! Você sabe que eu (tenho) vindo para você aqui para que disputa com Behezti e com Ananki filho de Aai. Levante-se contra eles, você e também seus pais, seus irmãos, e seus parentes e derrubem Behezti e Anankhi, o filho de Aai.

Lembre o que você disse para o Iy filho de Irti (isto é meu) "São as casas dos ancestrais que devem ser mantidas", quando você também disse "É a casa de um filho e depois a casa de seu filho". Possa o seu filho manter sua casa como você manteve a casa do seu pai.

O filho de Irti e de Sankhenptah - Yi - é o responsável pela mensagem de conclusão da missiva:

- O Sankhenptah, meu pai, possa agradar-lhe ter Ini sido encarregado por você de retomar a posse da casa de Anankhi, nascido para Wabut." (Wente, 1990:211)

Edda Bresciani, resumindo a missiva, explica que se trata da carta de uma viúva ao seu marido. Irti, a mulher, diz que enquanto estava ao lado do leito do morimbundo, chegou um mensageiro de Behseti, um dos culpados contra os quais ela apelava. $O$ agonizante confia o filhinho aos cuidados do representante de Behezti, ameaçando-o com a ira do avô Yi o velho, se o filho fosse privado da herança.

Apesar das últimas vontades no leito de morte, uma mulher chamada Wabut e um certo Izezi, talvez seu marido, tomaram posse da casa de Sankhenptah, de suas coisas e também de suas três criadas. A viúva, numa frase transparente,disse que preferiria que o marido a viesse buscar a ver o filho, de ambos, na dependência do filho de Izezi. Irti, certa de seus direitos, lembrava as palavras do marido, na hora da morte, e se perguntava como o defunto podia ficar calmo diante da iniqüidade de tais ações.

Bresciani enfatiza o ato da viúva de apelar por vingança, para uma inteira legião de mortos. Isso, em verdade, era um processo considerado normal em que um morto era uma das partes e o Deus o Juiz. Os mortos eram chamados mais como testemunhas de apoio ${ }^{4}$.

Para esta egiptóloga restam algumas interrogações atualmente impossíveis de responder: porque Behezti foi considerado mau a ponto de merecer punição maior que a de Wabut? Era talvez um chefe de família ou ele mesmo um morto?

\section{2) Carta de um marido para a mulher morta ( Ankhiry):}

"Para o competente espírito Ankhiry:

O que eu fiz para você estar com esta má vontade para comigo? O que eu fiz contra você? (..) Desde a época em que eu vivia com você como marido até hoje, 
o que eu fiz contra você que tenha que esconder? O que eu fiz contra você? Pelo que você fez, esta é a razão de meu lamento contra você, porém, que fiz eu contra você? Eu vou discutir legalmente com você na presença da Enneade do Oeste $e^{5}$ será decidido entre você e mim através desta carta porque eu escrevi sobre uma querela com você.

$O$ que fiz eu contra você? Eu a tomei como esposa quando eu era jovem tanto que eu estava com você enquanto eu me desempenhava bem em qualquer tarefa (...). Eu não me divorciei de você e não lhe dei motivo para se envergonhar. (...) E quando qualquer visitante chegava a mim em sua presença, não os recebia com consideração a você, dizendo "eu farei de acordo com o seu desejo"?

Veja, você não está deixando minha mente descansar. Eu vou discutir com você e o certo será distinguido do errado. Quando eu instruía os oficiais para a infantaria e as carruagens do Faraó, eu os trazia e os fazia reverenciar você, trazendo todo o tipo de coisas finas para colocar na sua frente. Eu não lhe escondi nada durante toda a vida. Eu não lhe causei, nem deixei sofrer qualquer tipo de desconforto nas coisas que eu fiz com os modos de cavalheiro. E nem você me viu trapaceando com modos de camponês, entrando em casa estranha. Eu nunca deixei que um censor achasse qualquer falha naquilo que eu fiz com você.

Quando fui designado para o posto em que eu estou agora, eu me tornei incapaz de sair, como era meu hábito. Tive que fazer aquilo que outro que está na minha situação faz quando está em casa, no que tange seu óleo ${ }^{6}$, seu pão e suas roupas e eles seriam levados até você. Eu não os dirigi para outro lugar mas disse: "A mulher ainda está comigo?". Assim eu disse e não trapaceei.

Agora veja, você está menosprezando o quão bem a tratei. Eu estou lhe escrevendo para deixá-la consciente das coisas que você está fazendo. Quando você adoeceu com a doença que contraiu, eu procurei um médico importante, e ele a tratou e fez o que você lhe pediu.

Quando eu fui acompanhar o Faraó em sua jornada para o sul, esta condição (isto 'é a morte) a derrubou, e eu passei diversos meses sem comer ou beber como uma pessoa normal. Quando eu cheguei a Mênfis, implorei uma licença para o Faraó e fui até onde você estava. Eu e meus parentes choramos entristecidos por você em frente de seu corpo (...). Eu doei roupas de fino linho para vestíla e fiz muitas roupas. Eu não vislumbrava nada bom que não tivesse feito para você.

Veja, eu passei estes últimos três anos sem entrar em outra casa muito embora isto não seja próprio para um que está na mesma situação. Eu fiz isto em consideração a você. Veja, você não diferencia o bem do mal. Alguém vai julgar a mim e a você. Quanto àquelas irmãs do lar, eu não penetrei dentro de nenhuma delas (sexualmente)"(Wente,1993.p.216).

Edda Bresciani resume com objetividade o teor da carta desse marido para a falecida: "Deixa-me em paz". O texto da XIX Dinastia, escrito em um papiro, foi encontrado em uma tumba de Mênfis, junto a uma estátua de madeira, possivelmente representando a defunta. Encontra-se atualmente no Museu de Leiden. Segundo Edda, o tom vivo e o conteúdo que ilumina singularmente a vida conjugal de uma família bem situada na sociedade egípcia, tornaram esta carta a mais conhecida e citada entre os documentos do gênero.

O fato de ser grafada em um papiro, material oneroso e reservado para documentos importantes, e a presença de uma estatueta de madeira, feita sob encomenda por um artista, são sinais exteriores do poder econômico do missivista ${ }^{7}$.

Bresciani fez algumas modificações no texto original, o que facilitou o entendimento do sentido das frases. Ela chama a atenção para o jejum que o viúvo disse ter feito durante oito meses de luto, em sinal de respeito à mulher. Destaca também o fato de ele não ter casado 
novamente, nem entrado em outra "casa". Segundo Manniche, esta expressão significa não ter tido relações sexuais.(Manniche, 1987.p.20)

Como Wente, Bresciani sugere que os problemas do viúvo de Ankhiri, desde a morte da mulher, eram de ordem sexual. Ele era um homem importante, a serviço direto do Faraó, pois, na carta, aparece pedido feito ao soberano para ausentar-se e acompanhar a mulher, na sua passagem para a outra vida. Apesar da destacada posição social, o viúvo não conseguia reorganizar sua situação afetiva e, pelo inusitado do caso, atribuía à ex-mulher a responsabilidade por isso.

$\mathrm{O}$ viúvo não se conforma com sua realidade. Ele culpava a morta pelos seus problemas. Sentindo-se injustiçado, expôs sua conduta íntegra durante a vida a dois. Isso incluía desde casar com a mulher, quando ele era jovem e fazia tudo muito bem, até o fato de manter-se fiel ao longo da relação. Tais atos, na visão do marido, mereciam agradecimento, pois eram incomuns e o distinguiam como uma pessoa particularmente boa. Entendemos por essa argumentação que a monogamia masculina, tal como existe hoje, era uma situação formal, que na prática merecia elogios e abria crédito ad eternum junto ao cônjuge.

$\mathrm{Na}$ época, o raciocínio e os argumentos foram certamente válidos; hoje, seria o caso de a mulher pedir para ser deixada em paz.

Dar à mulher um tratamento especializado, na doença, era também, no período, um fato valorizado pelo marido, dada a raridade desses acompanhamentos. O que mais chamou a atenção no caso, foi o empenho do viúvo em garantir que o médico fizesse tudo que a mulher solicitava e em enfatizar isso à mulher, quando afirmava textualmente que o médico a tratara da forma como ela lhe indicara ${ }^{8}$. A dúvida que fica a partir desta afirmação é grande. Pelo que sabemos, se Ankhiry parecia ser uma mulher preparada que conhecia os tratamentos, uma vez que o marido a invocava como "um competente espírito". Também parecia ser uma pessoa muito mimada, pois vimos, costumava receber presentes dos funcionários do marido. Dificilmente saberemos mais do que isso sobre as pessoas e sobre o relacionamento desse casal, exceto se novas cartas forem localizadas.

\section{3) Carta de um filho (Shepsi) para o pai (Inekhnmut) e para a mãe (Yi):}

Da XI Dinastia, selecionamos a missiva de um filho aos seus defuntos. Ele dizia ter sido bom para os pais, ter sido ofendido e pedia justiça contra um irmão morto anteriormente, que o apelante também tinha tratado com generosidade. Os problemas surgidos por causa da herança, entre a morte e o enterramento do pai, induziram-no a colocar a carta escrita, composta de duas partes, num pote, na tumba dos pais, na necrópole de Kau el Qebir.

$\mathrm{O}$ primeiro texto (a) é dirigido ao pai e o segundo (b) à mãe defunta.

\section{(3-a) Shepsi fala ao seu pai Inkhenemet:}

Este é um relato de sua viagem à prisão, o lugar onde estava Hetepu filho de Sen, quando você levou uma pata de boi e quando este seu filho veio com Enwaf e você disse:

_.Bem-vindos até mim vocês ambos! Sentem e comam a carne"!

Agora, devo eu ser mal tratado pelo meu irmão que está a seu lado, sem ter feito ou dito nada de mal? Eu o enterrei (...) e o depositei em sua tumba no deserto, ainda que tivesse a seu respeito um crédito de 30 medidas de trigo no Sul, uma roupa e um adereço Menu, 6 medidas de trigo do Sul, linho, um xale e uma $\operatorname{taça} a^{9}(\ldots)$.

Muito embora eu tenha feito por ele aquilo que nunca tinha sido feito antes por um irmão, ele maltratou este seu filho duramente, muito embora você 
tivesse dito a este seu filho: "Todas as minhas coisas ficarão para meu filho Shepsi". Mas eis que os meus campos foram tomados por Henu, filho de Sher. Eis que ele, o irmão defunto, está com você na mesma cidade. Eu (lhe peço) julgar-me com ele, pois os seus escribas estão com você na mesma cidade. Feliz o homem que fala enquanto os seus oficiais (o ouvem) (Bresciani, 1990. p.67).

Como este trabalho se baseia em uma revisão bibliográfica, é interessante apontar os impasses que surgem na busca de exatidão, em textos transliterados do egípcio antigo. Se compararmos a carta de Shepsi, na versão para o italiano de Bresciani, com a versão inglesa de Wente, a primeira mudança está na escrita do nome do remetente que de Scepsi em italiano passa a ser Shepsi. Há outras diferenças ainda.

$\mathrm{Na}$ tradução de Wente, Shepsi diz que enterrou o irmão entre os seus companheiros da necrópole e que Inkhenemet dissera textualmente:"É para o meu filho Shepsi que todas as minhas propriedades reverterão". Ao final, quando se queixa de que os campos foram tomados como possessão por Sher filho de Henu, o missivista questiona: "Pode um homem que maneja a lança ser alegre enquanto seus governantes são oprimidos?" (Wente, 1993, p.211).

Sem dúvida, a mensagem mais importante - o medo de ficar sem os campos e propriedades - está claro nas duas versões, bem como a admoestação sobre a ira dos deuses, se a injustiça não for sanada, se Inekhenmut não se manifestar imediatamente. Vejamos como Shepsi interpela Iy, a mãe:

\section{(3-b) Sobre o fato de você ter dito a este seu filho:}

"Traga-me algunas codornas para que eu possa comê-las!", e o filho lhe trouxe sete codornas e você as comeu.

Devo eu ser maltratado a seu lado? Estão os filhos descontentes com este seu filho?

É doloroso. Quem lhe servirá água? Possa você julgar a mime Sobekhotep! Eu o transportei de outra cidade e o coloquei na sua cidade, na sua necropóle, $e$ lhe dei roupas e tumba. Entretanto, ele maltrata este seu filho, sem que eu tenha feito ou dito nada de mal. O mal é doloroso para os deuses!'(Bresciani, 1990, p:68).

Diferentemente da carta ao pai, nesta Shepsi nomeia o irmão - Sobekhotep. Ele assusta a mãe com a possibilidade de lhe faltar água, se ele não a fornecer, e cobra retribuição e reconhecimento pelas sete codornas que lhe trouxera para comer. A ameaça velada, para o pai, torna-se incisiva para a mãe: a privação de água. ,

Ao final, Shepsi busca apoio dos deuses para os seu argumentos ao afirmar que eles não gostam de injustiças.

$\mathrm{Na}$ versão de Edward Wente, para o parágrafo derradeiro, fica corroborada a criação do medo: "Fazer algo errado é desagradável aos deuses!" (Wente, 1993. p.212).

\section{4) Carta de uma mulher (Dedi) ao marido defunto (o sacerdote Iniotef, filho de Inunakht):}

Todos, atualmente, valorizamos um trabalhador eficiente e, para a maioria dos empregadores, a perda de um auxiliar qualificado é um fato lamentável. Tudo indica que Dedi pensava assim também. Ela escreveu para o marido morto, no decorrer da XII Dinastia, em um pote:

O que você está fazendo a favor da serva Imiu que está doente? Você está combatendo por ela noite e dia contra qualquer homem que lhe faça mal ? Ou quer talvez que sua casa seja amargurada?

Combata por ela hoje e ainda de novo, que seja sólida a sua casa e que 
haja água para você!

Se não der ajuda, a sua casa será destruída. Não tem consciência do fato que é a sua serva que faz existir a sua casa entre a gente?

Combata por ela, vele por ela! Salve-a de todos aqueles que lhe fazem mal. Seja sólida a sua casa e os seus filhos. É bom escutar-me.(Brescianni,1990, p.69, Wente, 1993, p.215)

\section{5) Carta de um filho para o pai falecido.}

Quem falou pela primeira vez que "filhos criados, trabalhos dobrados" deve ter lido algo com o teor semelhante da carta, a seguir. Ela foi escrita, no decorrer do Primeiro Período intermediário, por um filho para o seu pai morto.

Este é um lembrete do que eu lhe falei sobre mim: "Você sabe que Idu disse em relação ao seu filho: 'Por aquilo que exista no além, eu não o deixarei padecer de nenhuma aflição 'Por favor, faça isto por mim.

Agora eu trouxe este suporte de jarra sobre a qual sua mãe deverá iniciar uma querela. Que lhe seja agradável apoiá-la. Além do mais, faça com que nasça um filho sadio para mim, pois você é um espírito hábil. Agora, em relação àquelas duas servas Nefertjentet e Itjai, que afligiram a Seny, confunda-as! E afaste de mim qualquer aflição dirigida contra minha esposa, de quem, você sabe, eu necessito. Afaste-as completamente, como você vive para mim; possa A Grande (Hathor?) ${ }^{10}$ favorecê-lo(?) e que a face do grande Deus possa gentilmente se virar para você e que ele possa dar-lhe pão puro de suas duas mãos. Além disso, é para sua filha que eu estou implorando um segundo filho sadio" (Wente, 1990, p.213).

Os medos desse missivista são de várias ordens: ele teme não vir a ter filho sadio, ele teme duas servas que afligiram sua mulher. Ele julga necessitar da companhia de Seny, a esposa, e teme perdê-la. Pede ao pai para confundir, ou melhor, despistar, afastar qualquer aflição dirigida contra sua família.

Ele acena para o pai com a possibilidade de receber os favores da Deusa Hathor, do amor e do pão puro, além de alegrar a Seny, que por ser sua mulher, era considerada como uma filha do morto.

Sabendo-se atualmente que pai é para "essas coisas" e que o medo é um sentimento presente na vida, a missiva consegue resgatar a antiguidade desta sabedoria.

\section{6) Carta de um marido a sua esposa falecida.}

A importância das pessoas influentes nas decisões terrenas também é um conhecimento antigo, explorado pelos humanos, em todos os níveis de relacionamento. É proveitoso referir uma carta, do Primeiro Período Intermediário, que mostra a valorização disso, na vida eterna.

“(...) Foi sem descontentamento na sua parte contra mim que você foi trazida para a cidade da Eternidade.

Se é o caso de que essas injúrias estão sendo infligidas contra sua vontade, seu falecido pai continua influente (na) necrópole. Se há alguma reprovação no seu coração, esqueça isto pela saúde de suas crianças. Seja bondosa, que os deuses do nomo ${ }^{11}$ Thinita serão bons para você" (Wente, 1993, p.214).

Esse marido parece acreditar que a esposa não é a responsável pelos problemas que sofre. Por isso, pede-lhe que fale com o pai influente na necrópole, e também morto, para ajudá-lo.

O marido admoesta a mulher morta, dizendo que os seus filhos também serão beneficiados com a ajuda dela. E os deuses serão generosos na medida em que ela o for. A chantagem emocional é leve em relação às outra missivas, mas reveste a carta de um tom prepotente, embirrento e 
orgulhoso. Isso nos instiga a pensar: será que as injúrias não eram cabíveis?

\section{7) Carta de uma mãe (Merti) ao filho (Mereri).}

Também do primeiro período intermediário, resgatamos uma carta de uma mãe para o filho morto:

"O Mereri nascido para Merti (quem escreve), possa Osiris, "o mais ilustre dos Ocidentais" prover você por milhões de anos, dando sopro para o seu nariz ${ }^{12}$ e dando pão e cerveja na presença de Hathor, senhora do Horizonte. Sua condição é como a de um que vive inúmeras vezes pela vontade dos deuses que estão no céu e na terra. Possa você criar obstáculos contra inimigos masculinos e femininos que estão maleficamente dirigidos para sua casa em direção do seu irmão $e$ da sua mãe.

É uma mãe que se dirige ao seu competente filho Mereri:

Como você era um dos que estavam em situação excelente na terra, assim você deve ser um dos que estão em boa situação na necrópole. Para você oferendas têm sido feitas; para você a festa 13 "haker" foi celebrada; para você a festa "wag" foi celebrada; e para você será dado pão e cerveja da mesa de oferendas do mais ilustre dos Ocidentais (Osiris). É no barco da noite que você viajará corrente abaixo, e no barco da manhã você navegará corrente acima. Para você será "dada a absolvição" na presença de todos os deuses. Seja no seu próprio interesse o mais "louvável" dos meus mortos machos e fêmeas. Você sabe que ele disse para mim, "Sou Eu que farei o relato sobre você e suas crianças". Relate sobre isto já que você está em lugar para justificar(Wente, 1993, p.214).

Essa mãe, orgulhosa de seu filho, pela situação que vivenciou na terra, acredita que, por tais razões, ele é bem sucedido na necrópole. Ela expõe todas as coisas boas que estão sendo feitas para ele, por seus familiares. Em troca, pede proteção; ela teme por ela e pelo outro filho.

A riqueza em detalhes da carta, que é extensa, revela uma mãe com conhecimento dos rituais religiosos e com poder aquisitivo capaz de oferecer esses rituais ao filho morto.

\section{8) Carta de um marido (Merirtyfy) para a esposa morta (Nebetiotef)}

Finalmente, de todas, a mais medrosa das cartas. É de um marido, no Primeiro Período Intermediário, que gravou em uma estela uma súplica para a esposa morta, expressando um temor profundo pela saúde, como segue:

Como está você? Está o ocidente cuidando de você (conforme) seu desejo? Desde que eu sou o seu amado na terra, lute em meu favor e interceda em meu benefício. Eu não deturpei sua presença quando eu perpetuei o seu nome sobre a terra. Remova a enfermidade do meu corpo! Por favor, torne-se um espírito para mim (em frente) a meus olhos. Então eu poderei ver você, como em um sonho, lutando a meu favor. Eu depositarei oferendas para você (tão logo) o sol levante (...) (Wente, 1993, p.215).

Os exemplos seriam mais numerosos para, fundamentalmente, expressar os receios já nomeados. O que hoje denominamos família, parentesco e casamento, significando consangüinidade e afinidade entre as pessoas, também existiu no Antigo Egito.

Segundo Arendt, o puro nomear das coisas, a criação de palavras, é a maneira humana de "apropriação", de desalienação do mundo, no qual cada um de nós, nasce como um recémchegado, como um estranho (Arendt, 1992, p.77). Assim, entendemos que o núcleo familiar do egípcio antigo manifestava temores muito semelhantes aos que hoje vivemos.

De fato, dessa organização egípcia, nàda há que nos surpreenda totalmente ou que evo- 
que a África primitiva ou que anuncie o Islã. A célula ordinária foi, como entre nós, uma "família restrita", efêmera e liberal: um marido, uma mulher, com uma grande independência moral e financeira, e os filhos não emancipados.

Pelas cartas aos mortos, vimos que tais relações eram ainda mais fortes do que pensávamos: ultrapassavam os limites da vida terrestre e envolviam os mortos em uma teia de interesses mútuos com os vivos. Era um processo que poderíamos chamar de "toma lá, da cá".

\section{Comentários e conclusões}

Pelo exposto, vimos que o medo foi um sentimento fácil de ser resgatado das mensagens veículadas entre os vivos e os mortos, no Egito Antigo.

Das oito cartas apresentadas, identificamos diferentes tipos de medo: de empobrecimento; de injustiças e injúrias; da falta de serviçais eficientes; da ausência de pessoas queridas; da impossibilidade de gerar filhos saudáveis; e, finalmente, da perda da própria integridade física. Em nenhuma destas missivas, apareceu o medo de perder a razão. Por que será? Este é assunto para um próximo estudo.

\section{Notas}

1 - Sobre o aprendizado da escrita pelas mulheres, ver Janssen, J.J \& Janssen, R. Growing up in Ancient Egypt. London: The Rubicon Press, 1990.

2 - Sobre o uso de tecidos, ver Hall, R. Egyptian Textiles. London: Shire Publications, 1986.

3 - Ha é o deus do deserto, especialmente das regiões do ocidente, incluindo os oásis. Ele protege o Egito das invasões externas, espacialmente as vindas da Líbia. Ver Hart, G. Egyptian Gods and Goddesses. London: Routledges \& Kegan, 1986.

4 - Sobre os julgamentos, ver Breasted, J.H. Ancient Records of Egypt. London: Histories and Mysteries of Man, $19885^{\circ} \mathrm{v}$.

5 - A palavra Enneade é do grego e designa os deuses de Heliópolis: Atum, Shu e Tefnut, Geb e Nut, Osiris, Isis, Néftis e Seth.

6 - Entendemos do texto que cabia ao homem prover a casa das coisas necessárias. Ver Strouhal, E. Life of Ancient Egyptians. Oklahoma: Oklahoma Press, 1992.

7 - Ver Adams, B. Egyptian mummies. London: Shire Publications, 1984.

8 - Ver Reeves, C. Egyptian medicine. London: Shire Publications, 1992.

9 - O adereço Menu/Menat é, segundo Bunson, um amuleto. Inicialmente uma peça de jóia simbólica, para Lurker ele torna-se um colar grande e pesado. Como um atributo de Hathor possui poderes divinos de cura (Lurker,1974, p.79).

10 - Ver Hart, G. op. cit. nota 3.

11 - A palavra nomo vem do grego e se refere a uma província ou região administrativa do Antigo Egito, denominada sepat na língua egípcia.

12 - Ver Budget, E.A. O livro egípcio dos mortos. São Paulo: Melhoramentos, 1923.

13 - Sobre as festas há a Tese de Doutoramento de Louis Boctor Mikhail:Dramatic Aspects of the Osirian Khoiak Festival. Upsalla, 1983. 


\section{Referências bibliográficas}

ARENDT, H. Entre o passado e o futuro. São Paulo: Perspectiva, 1968.

BUNSON, M. Ancient Egypt. New York: Facts on File, 1991.

BRESCIANI, E. Letteratura e Poesia dell'Antico Egitto. Torino: Einaudi, 1990.

CERTEAU, M. de. A escrita da História. Rio de Janeiro: Forense, 1982.

LURKER, M. The Gods and symbols of the Ancient Egypt. London: Thames \& Hudson, 1974.

MANNICHE, L. Sexual life in Ancient Egypt. London: Routledge \& Kegan Paul, 1987.

POSENER, G. Dictionnaire de la civilisation égyptienne. Paris: Fernand Hazan, 1988.

SPENCER, A. J. Death in Ancient Egypt. London: Penguin Books, 1982

WENTE, E. Letters from Ancient Egypt. Atlanta: Scholars Press, 1990.

BAKOS, M. M. Not always a friendly relationship: the Egyptians and their dead. Classica, São

Paulo, 7/8: 15-24, 1994/1995.

ABSTRACT: The Egyptian view was that the afterlife was to a certain extent a prolongation of this life. Therefore, it was not unusual that the Ancient Egyptians sought to communicate with their deceased relatives. The aim of this work is to show that in many letters the fear of something was one of the most importan reasons for this kind of communication.

KEY-WORDS: Egypt, letters, deads, fear. 